\title{
Becoming a Supervisor: Per Osmosis, Modeling or Training?
}

\author{
Richard Balon $^{1} \cdot$ Mary K. Morreale ${ }^{1} \cdot$ Rashi Aggarwal $^{2} \cdot$ John Coverdale ${ }^{3} \cdot$ Anthony P.S. Guerrero $^{4} \cdot$ Alan K. Louie $^{5}$. \\ Eugene V. Beresin ${ }^{6} \cdot$ Adam M. Brenner $^{7}$
}

Published online: 15 April 2021

(C) Academic Psychiatry 2021

\section{Quis custodiet ipsos custodes?}

("Who shall keep watch over the guardians?")

-Juvenal

Presumably most, if not all, psychiatrists have supervised someone during their career, such as medical students, residents, fellows, other physicians, and mental health professionals, including psychologists, social workers, various therapists, nurse practitioners, and physician assistants. A psychiatrist might act as a supervisor in many different situations, contexts, and settings.

The role of the clinical supervisor in educational settings is an important task, with responsibility not only for the clinical service provided by supervisees but also for their education. As pointed out by Markman and Cowley [1], "clinical supervision is central to psychiatric education." The important role of supervision in psychiatric education is recognized by the requirement of the Accreditation Council for Graduate Medical Education (ACGME) that residents at all levels of training must be provided at least 2 hours of faculty supervision weekly, 1 hour of which must be individual [2].

Though clinical supervision has a vital role in undergraduate and postgraduate clinical education, "it is probably the

Richard Balon

rbalon@wayne.edu

Wayne State University, Detroit, MI, USA

2 Rutgers New Jersey Medical School, Newark, NJ, USA

3 Baylor College of Medicine, Houston, TX, USA

4 University of Hawai'i John A. Burns School of Medicine, Honolulu, HI, USA

5 Stanford University, Stanford, CA, USA

6 Harvard Medical School, Boston, MA, USA

7 University of Texas Southwestern Medical Center, Dallas, TX, USA least investigated, discussed and developed aspect of clinical teaching" [3]. Some disciplines, for instance, psychology and psychoanalysis and other psychotherapy schools in general, have devoted time and energy to address the complexity of supervision and the development of supervisors. Unfortunately, in our opinion, the field of psychiatry has not paid enough attention to supervision as a process and as an issue of professional development. One exception is the excellent book edited by Drs. De Golia and Corcoran [4] that addresses in detail a number of issues related to supervision, including supervision formats, techniques, and clinical and non-clinical venues. This lack of attention seems to be a symbolic reflection of psychiatry's lack of interest in an issue central to this editorial: How does one become and develop as an effective supervisor?

\section{How Is Supervision Defined?}

The definition of supervision depends on many factors, including the venue and situation; the nature of the relationship (e.g., hierarchical vs. collaborative); knowledge, skills, attitudes, and values necessary for competence; approaches to evaluation and feedback; and the ability to reflect on supervisor and supervisee [5]. Although our focus in this editorial is on clinical supervision in academic, educational settings, and context, it is important to consider other broader definitions, as well, including those outside academic environments.

Falender and Shafranske ([6], cited in [5]) define clinical supervision as follows:

.... a distinct professional activity to which education and training aimed at developing science-informed practice are facilitated through a collaborative interpersonal process. It involves observation, evaluation, feedback facilitation of supervisee self-assessment, and acquisition of knowledge and skills by instruction, modeling, and 
mutual problem-solving. Building on the recognition of the strengths and talents of the supervisee, supervision encourages self-efficacy. Supervision ensures that [it] is conducted in a competent manner in which ethical standards, legal prescriptions, and professional practices are used to promote and protect the welfare of the client, the profession, and society at large. (p. 3)

They add that effective supervision encourages supervisee development and autonomy and enhances both patient and supervisee outcomes ([6], pp. 1031-2).

Kilminster and colleagues ([7], p. 3) provide a simpler definition of supervision being "the provision of guidance and feedback on matters of personal, professional and educational development in a context of a trainee's experience of providing safe and appropriate patient care."

Furthermore, in the discussion of psychiatrists' relationship with nonmedical therapists, the American Psychiatric Association ([8], p. 1490) states the following:

In a supervisory relationship the psychiatrist retains direct responsibility for patient care and gives professional direction and active guidance to the therapist. ... The psychiatrist remains ethically and medically responsible for the patient's care as long as the treatment continues under his or her supervision. The patient should be fully informed of the existence and nature of, and any changes in, the supervisory relationship.

The first two definitions described above have commonalities, whereas the third seems unrelated to the educational aspects of and professional development that derives from supervision. Given that psychiatry, as practiced today, regularly relies on collaboration with nonmedical therapists and advanced practice providers, how to supervise this additional workforce should become part of trainee supervision. Thus, all three definitions are important to consider in discussing and defining a supervisor's role.

Supervision also involves legal aspects, as discussed by Sederer, Ellison, and Keyes [9]. They define it as "a mandated relationship between two professionals in which one - the supervisee - is generally obliged to follow the recommendations of the other - the supervisor - over a period of time" ( $p$. 1199). They also note that the responsibility of the supervisor for quality of care and malpractice is well established and that supervision should reflect national standard of care and ensure that this standard is met [9].

\section{Characteristics and Duties of Supervisors}

The characteristics of a good supervisor in clinical psychiatry in particular, and in medicine in general, have not been adequately explored. As a result, opinions about what defines a good supervisor may differ. The trainees' view of who is a good supervisor may be different than that of a program's or institutional leadership. How should qualities of warmth or knowledge or their lack be weighed relative to performances in following rules and regulations or completing evaluations in a timely manner or for providing formative feedback that is timely, mutual, seamless, and amenable to modification of behavior [10]? How should supervisors who are loved for praise and a lack of criticism be compared with those who are less liked but who are more constructively critical of those whom they supervise? Characteristics of an effective supervisor are also difficult to separate from the essential duties that a supervisor needs to follow and accomplish.

Kilminster and colleagues ([7], p. 7) felt that an effective supervisor, in addition to supervisory skills, should possess good interpersonal and teaching skills and be clinically knowledgeable and competent. They outlined both helpful and ineffective supervisory behaviors. According to them, the former includes giving direct guidance in clinical work, linking theory and practice in problem-solving, offering feedback and reassurance, and being a good role model. They posited that less effective behaviors included being rigid, lacking empathy, not offering support, not addressing the supervisee's concerns and concerns about the supervisee, emphasizing negative aspects of the supervisee, being indirect, and not teaching. They also proposed that good supervisors should possess knowledge and exhibit qualities of warmth, empathy, good listening skills, respect, and support of others and being positive and enthusiastic. These traits promote the kind of safe environment in which a trainee is likely to candidly relate issues and problems in their work and elicit clear feedback. Further relevant skills include effective problem appraisals, counseling, negotiation, and communications with appropriate emotional regulation and being able to involve trainees in problem solving and provide opportunities for clinical practice with constructive feedback [7]. Finally, their list of good teaching skills includes knowledge of teaching resources, offering an opportunity to carry out procedures or clinical activity, giving directions, individualizing the teaching approach, being available, and having effective evaluation skills.

Both Falender and Shafranske [5] and Kilminster and colleagues [7] described components of effective supervisory practices and abilities beginning with demonstrating respect for the supervisee and patient, creating a supervisory climate, clarifying roles and expectations, and being able to observe and reflect on practice. They also included assessing competencies and giving constructive feedback anchored in these competencies, forming a supervisory alliance with identification and repair of strains in the supervisory relationship, motivating the supervisee, fostering autonomy, teaching, providing information, managing the service, and engaging the 
supervisee in skill development, among many others. The effective supervisor should also explore and address transferential and countertransferential issues in both the superviseepatient and supervisor-supervisee relationship, as these can be related. As Searles [11] reminds us of the informational value of the psychotherapy supervisor's emotional experience, "the processes at work currently in the relationship between patient and therapist are often reflected in the relationship between therapist and supervisor," here supervisee and supervisor (p. 199).

We would like to also emphasize that in psychiatry, supervisors play an essential role in ensuring that diagnostic and therapeutic tools include the ability to empathize with patients and to process information gathered from self-reflection. Supervisors also play an important role in helping supervisees to maintain well-being and engage in their professional role. Finally, certain milestone competencies, such as reflective practice and commitment to personal growths, are optimally developed and assessed via the supervisory process.

Acceptance of these characteristics and skills as important for providing good and effective clinical supervision raises many questions. Not every supervisor possesses all these characteristics and skills. Should we consider these skills and may be other ones mentioned in the literature for the selection of supervisors? Would it be realistic and practical? Should we create competencies akin to those created by regulatory agencies for residents and medical students? How do supervisors address and develop new skills addressing the reality of new situations, such as supervising virtually, including running a virtual meeting with the supervisee and patient? Should we promote, teach, and train supervisory skills? Should training of supervisory skills be a part of professional development? Should supervisory skills be outlined in our programs and be used for supervisors' evaluations? If yes, who should conduct these evaluations and how should they conduct them and using what data? How do we build a cadre of effective clinical supervisors? What do we do with an ineffective, difficult, or even abusive supervisor? What is the role of supervisory contracts, and how do these agreements support the role of supervisory relationships [12]?

\section{How to Become a Supervisor}

The discussion of the way one becomes a supervisor brings us to the title of this editorial: whether one is born a good supervisor or becomes a good supervisor per osmosis, modeling, or training. Relying on someone being "born" an effective supervisor or becoming one per "osmosis" (defined here as the gradual and/or unconscious assimilation of supervisory characteristics and skills) is probably naïve, difficult, and unreliable. We should also avoid the traditional, simplistic approach of "see one, do one, teach one." We clearly need to understand the enculturation and educational processes of becoming a supervisor that include both modeling and training and a host of other activities, such as didactics and seminars. We also need to establish where this education should occur and in what setting(s) these processes should play out. Workshops, lectures, seminars, manuals, or structured peer observations, objective structured teaching exercises [13-17] and courses at local and national educators' meetings facilitated by reading texts such as the De Golia and Corcoran book [4] are a good start but likely not enough. The development of supervisors should be a continuous process happening in the clinical setting and/or in supervisory meetings (in addition to didactic instruction) with proper feedback and evaluation of yet-to-be established supervisors of supervisors.

Watkins [18] emphasizes the developmental perspective or process in supervisor training, that is, moving from lack of confidence and limited supervisory skills to comfort, confidence, and solidified supervisory skills and identity (p. 287). One of the most difficult issues could be a determination of whether anybody should serve as supervisor (of trainees or other clinical workers) and what the initial qualification should be (e.g., certification by the American Board of Psychiatry and Neurology, Inc. [ABPN] or another specialty board, length of period post-residency before one is able to supervise, clinical experience, previous evaluations, different requirements for teaching clinical supervisors vs. nonteaching service supervisors).

In their discussion of designing a professional development program for supervisors in general, Markman and Cowley [1] suggest that such programs could include "direct observation of supervision itself, view of video recording of past supervision, discussion of the process noted, or some combination of these options. Such supervision would allow for observation and feedback as well as reflection for the training supervisor on the process of supervision from both sides" (p. 415). This approach seems suitable for individual supervisory sessions, but it is not clear how it would be extrapolated to reflect on clinical onsite training, such as supervision during rounds or giving individual feedback during specific onsite clinical supervision. And process notes may not always reflect the full picture, either.

In a discussion of what training supervisors need and how the effectiveness of supervision can be determined, Kilminster and colleagues ([7], p. 8) recommend that supervisor training should include an understanding of teaching, assessment, appraisal and feedback, career advice, and interpersonal and counseling skills. The authors also felt that training should emphasize the importance of understanding the purpose, role, types, levels and concept of supervision, a knowledge and understanding of supervisee training, interpersonal dynamics, and giving and receiving criticism.

Interestingly, Falender and Shafranske [5] suggested the creation of a supervision contract/informed consent outlining 
an integrated plan for supervision that would include and clarify the supervisor and supervisee expectations and responsibilities and the supervisor's duties and roles. Some elements that should be included in such a contract are the scope and practice under supervision, appropriate preparation for both parties, the length of supervision and the supervision contract, specific roles and expectations of the supervisor and supervisee, and policies regarding cancellations and emergencies. Additional elements may include expected processes (e.g., direct observation, mutual observation and analysis of videotaped sessions, modeling), expected preparation, a plan for feedback anchored in competencies, and specification of evaluation measures and their timing. A contract as such should include a discussion of confidentiality and its limits with reference to codes of ethics and state laws to report (e.g., programs, hospitals, licensing boards), as well as expectations relevant to the needs of specific settings (e.g., remote supervision, as required during the COVID-19 pandemic). Finally, a contract should address issues related to diversity in supervisory training [3]. Kilminster and Jolly [3] also emphasized the importance of finding time for supervision and time management during the supervisory process. They suggest that time spent in supervision may be counterbalanced by the more effective working of supervisees. There is little in the way of empirical evidence supporting the use of contracts in supervisory relationships across the mental health professions, however [12]. The elements of a thorough contract could serve as a contextual base for developing a specific program for supervisory training in each residency training program.

\section{Conclusion}

Effective supervision is clearly a crucial element in psychiatric education, to which, we suggest, we have not been paying enough attention. It is obviously a more complex and complicated element of education that has been less well appreciated. The fundamentals of effective supervision are the proper concept of supervision (definition, what it should include) and the development of the key personnel-effective, well-versed, clinical, and other supervisors.

We have outlined some of the issues related to the definition and characteristics of supervision, the unique skills of supervisors, and the need for supervisor training. We are not implying that the supervision we are currently providing is ineffective or of low quality. We suggest that we need to articulate, develop, and demonstrate the skills requisite to effective supervision while taking a pause to think about the issues described here. Is the supervision provided truly effective and helpful in its different contexts? Is there a way to make it better? Are we doing a disservice to our field and our patients by not always including good supervisor education and training as a part of our professional development?
Our field likely needs to develop standards for the faculty who provide supervision to psychiatric trainees and other mental healthcare providers. Should there be competencies for supervisors established akin to the competencies currently used in residency education? Some of the supervisory skills we have discussed already reflect the core competencies outlined by accrediting bodies such as the ACGME in the USA, for example, interpersonal and communications skills. When should supervisor training begin? We recommend that it should it be included in residency training (residents supervise medical students and senior residents supervise interns). We also believe that we should not only train the "novices" but also retrain standing supervisors, at least those who seem to be ineffective or have other issues. Finally, we need to decide what organizations should take this issue on.

We agree with Markman and Cowley [1] that there are two major obstacles on the road to develop effective supervisors: lack of experts/expertise and lack of resources. However, it is clear to us that we need to develop a deeper discussion on training issues related to supervision, as it would lead to improved education and better patient care. Supervision is a specific skill set that should be defined in terms of the core knowledge, skills, and attitudes requisite for implementing a particular model or hybrid model of clinical intervention. We need clearly defined outcome measures to demonstrate efficacy of supervision, by observation, video analysis, simulation, and other means of ongoing faculty development. After all, supervision is one of the most important ways we transmit the evidence-based methods we teach our residents. And, through ongoing supervision in a number of contexts, we can say with veracity that our graduates are capable of practicing in an ethical, professional, competent, and independent manner. This is our duty to the field and our contract with the ACGME to certify residents on completion of training. Thus, well-conceptualized development of those who provide clinical and other supervision, that is, competent, effective, and skillful supervisors, is an issue of utmost importance. We cannot rely on osmosis combined with a little bit of modeling in developing supervisors anymore. National (e.g., the American Association of Directors of Psychiatric Residency Training, ABPN, or ACGME) or international educational organizations can assist by developing an acceptable definition and framework of supervision and supervisor education and training (the expertise obstacle), with relevant regulatory organization/agencies helping us to address the lack of resources obstacle. These are challenges worthy of our sustained attention.

\section{Declarations}

Disclosure On behalf of all authors, the corresponding author states that there is no conflict of interest. 


\section{References}

1. Markman JD, Cowley DS. Professional development. Strategies for supervision and growth of supervisors. In: Supervision in psychiatric practice. Practical approached across venues and providers. Edited by De Golia SG, Corcoran KM. Washington, D.C.; American Psychiatric Association Publishing; 2019; pp 409-418.

2. Accreditation Council for Graduate Medical Education. ACGME Program Requirements for Graduate Medical Education in Psychiatry. p 30 (accessed February 12, 2021).

3. Kilminster SM, Jolly BS. Effective supervision in clinical practice settings: a literature review. Med Educ. 2000;34:827-40.

4. De Golia SG, Corcoran KM. Supervision in psychiatric practice. Practical approaches across venues and providers. Washington, D.C.; American Psychiatric Association Publishing, Inc., 2019.

5. Falender CA, Shafranske EP. Clinical supervision: the state of art. J Clin Psychol. 2014;70:1030-41.

6. Falender CA, Shafranske EP. Clinical supervision: a competencybased approach. Washington, D.C.; American Psychological Association, 2004.

7. Kilminster SH, Cottrell D, Grant J, Jolly BS. AMEE Guide No. 27: Effective educational and clinical supervision. Med Teach. 2007:29(1):2-19.

8. American Psychiatric Association. Guidelines for psychiatrists in consultative, supervisory, or collaborative relationship with nonmedical therapists. Am J Psychiatry. 1980;137:1489-91.

9. Sederer LI, Ellison J, Keyes C. Guidelines for prescribing psychiatrists in consultative, collaborative, and supervisory relationships. Psychiatr Serv. 1998;49:1197-202.
10. Ende J. Feedback in clinical medical education. JAMA. 1983;250: 777-81.

11. Searles HF. The informational value of the supervisor's emotional experiences. Psychiatry. 2015;78:199-211.

12. Lu D, Suetani S, Cutbush J, Parker S. Supervision contracts for mental health professionals: a systematic review and exploration of the potential relevance to psychiatry training in Australia and New Zealand. Australasian Psychiatry. 2019;27:225-9.

13. Riess H, Herman JB. Teaching the teachers: a model course for psychodynamic psychotherapy supervisors. Acad Psychiatry. 2008;32:259-64.

14. Milne D. Can we enhance the training of clinical supervisors? A national pilot study of an evidence-based approach. Clin Psychol Psychother. 2010;17:321-8.

15. Mookherjee S, Monash B, Wentworth KL, Sharpe BA. Faculty development for hospitalists: structured peer observation of teaching. J Hosp Med. 2014;9:244-50.

16. Boillat M, Bethune C, Ohle E, Razack S, Steinert Y. Twelve tips for using the Objective Structured Teaching Exercise for faculty development. Med Teach. 2021;34:269-73.

17. Julian K, Appelle N, O'Sullivan P, Morrison EH, Wamsley P. The impact of an Objective Structured Teaching Evaluation on faculty teaching skills. Teach Learn Med. 2012;24:3-7.

18. Watkins CE Jr. Educating psychotherapy supervisors. Am J Psychother. 2012;66:279-307.

Publisher's Note Springer Nature remains neutral with regard to jurisdictional claims in published maps and institutional affiliations. 